\title{
Thymosin $\beta 4$ promotes the survival and angiogenesis of transplanted endothelial progenitor cells in the infarcted myocardium
}

\author{
ZHE QUAN $^{1 *}$, QIANG-LI WANG ${ }^{2 *}$, PEI ZHOU ${ }^{1}$, GUO-DONG WANG ${ }^{1}$, YU-ZHEN TAN $^{1}$ and HAI-JIE WANG ${ }^{1}$ \\ ${ }^{1}$ Department of Anatomy, Histology and Embryology, Shanghai Medical School, Fudan University, Shanghai 200032; \\ ${ }^{2}$ School of Basic Medical Sciences, Shanghai University of Traditional Chinese Medicine, Shanghai 201203, P.R. China
}

Received July 19, 2016; Accepted March 20, 2017

DOI: $10.3892 /$ ijmm.2017.2950

\begin{abstract}
The survival of transplanted stem cells in ischemic tissue is poor. In the present study, the effects of thymosin $\beta 4$ (T $\beta 4$ ) on the survival and angiogenesis of endothelial progenitor cells (EPCs) and improvement in cardiac functions after transplantation of T $\beta 4$-treated EPCs in the infarcted myocardium were investigated. EPCs were isolated from bone marrow of adult male rats and incubated in Endothelial Basal Medium-2. Then the cells were treated with $\mathrm{T} \beta 4$ at different concentrations $(0.05,0.1$ and $0.2 \mu \mathrm{M})$, and cells incubated with DMEM were set as controls. MTT assay, Transwell assay and tube formation in Matrigel were used to detect cell viability, migration and angiogenesis, respectively. For examining the protective effect of T $\beta 4$ on EPCs, the cells were also incubated in the condition of hypoxia and serum deprivation. p-Akt expression was also examined using western blot analysis. Rat models of myocardial infarction (MI) were established by ligation of the anterior descending branch of the left coronary artery. At four weeks after intramyocardial injection of T $\beta 4$-treated EPCs, the changes in cardiac functions, size of the scar tissue and density of microvessels were examined by echocardiography, Masson's trichrome staining, immunohistochemistry and fluorescence in situ hybridization (FISH) for the Y-chromosome. $\mathrm{T} \beta 4$ enhanced EPC viability, protected the cells from apoptosis in hypoxia and serum deprivation, and promoted the proliferation and migration of the cells and formation of capillary-like structures in the cells. Moreover, T $\beta 4$ increased p-Akt expression in the cells. The cytoprotective and proangiogenic effects of T $\beta 4$ were in a dose-dependent manner. T $\beta 4$-treated EPCs
\end{abstract}

Correspondence to: DrHai-Jie Wang or Dr Yu-Zhen Tan, Department of Anatomy, Histology and Embryology, Shanghai Medical School, Fudan University, 138 Yixueyuan Road, Shanghai 200032, P.R. China E-mail: hjwang@shmu.edu.cn

E-mail: yztan@shmu.edu.cn

*Co-first authors

Key words: endothelial progenitor cells, thymosin $\beta 4$, transplantation, angiogenesis, myocardial infarction improved cardiac function, enhanced the repair of the infarcted myocardium, and promoted angiogenesis after transplantation in the infarcted myocardium. In conclusion, pretreatment of EPCs with T $\beta 4$ is a novel strategy for the repair of ischemic tissue after transplantation in MI.

\section{Introduction}

Myocardial infarction (MI) is one of the main causes of death and disability in both developed and developing countries. According to the statistics of the American Heart Association (AHA), approximately every $43 \mathrm{sec}$, one American suffers MI (1). In 2011, 160,000 individuals died of MI (1). In China, cardiovascular disease is the leading cause of death and acute MI has become the primary cause of cardiac-related deaths in 2013 (2). MI not only affects human health, but also results in a heavy financial burden to the patients' family and society. Thus, exploring effective therapies for MI is of great importance for improving the health status of populations in China and worldwide.

MI is characterized by the loss of function of cardiomyocytes caused by reduced blood supply from coronary arteries to the heart (3). In patients with MI, necrotic myocardium is gradually replaced by scar tissue, leading to loss of cardiac contraction and possibly to heart failure. A variety of therapeutic methods for treating MI have been applied in the clinic such as coronary intervention (4), thrombolytic therapy (5) and drug therapy [anticoagulants (6), $\beta$-blockers ( 7$)$, angiotensinreceptor blockers (8) and antiarrhythmic drugs (9)]. The main goal of the current clinical treatment is revascularization after MI. Successful revascularization can increase the blood supply to the infarcted area and effectively reduce the myocardial necrosis of the remaining healthy myocardial cells. Reperfusion is an effective method for tissue survival, yet it may lead to tissue damage, such as cardiomyocyte loss and microcirculatory disturbances during the pathological process of ischemia-reperfusion injury in prolonged myocardial ischemia (10). As mentioned previously, cardiomyocytes regenerate at $\sim 1 \%$ year throughout human life, thus the capacity for regeneration is limited (11). Notably, cardiomyocytes are incapable of sufficient regeneration to correct cell losses after MI (11). Therefore, therapeutic strategies stimulating cardiomyocyte 
renewal may be an effective method for treating cardiac pathologies, and cell transplantation for cardiomyocyte renewal has attracted increased attention for cardiac dysfunction after MI.

Endothelial progenitor cells (EPCs) are derived from peripheral mononuclear cells that can differentiate into vascular endothelial cells (12). EPCs play important roles in angiogenesis after birth and repair of injured endothelium (12). When required for vascular repair or angiogenesis, circulating EPCs migrate to the areas of endothelial damage, differentiate into vascular endothelial cells and aggregate to form new vessels (13). Previous studies have demonstrated the promoting effects on angiogenesis following transplantation of EPCs in the infarcted area $(14,15)$. However, most EPCs die after transplantation due to inflammation and presence of apoptotic factors, leading to insufficient capacity of EPC transplantation for treating cardiac disease $(16,17)$. The key for treating MI is promoting the survival and function of EPCs after transplantation.

Thymosin $\beta 4$ (T $\beta 4)$ is a pleiotropic polypeptide and is abundantly expressed in EPCs (18). Recent studies indicate that $\mathrm{T} \beta 4$ is involved in angiogenesis, and may promote endothelial cell differentiation, migration and angiogenesis in vitro $(18,19)$. Thus, in the present study, we incorporated both in vitro and in vivo animal experiments to explore the cardioprotective roles of T $\beta 4$ on EPC-based transplantation in rats and to further investigate the mechanisms underlying the cardioprotective effects of EPCs.

\section{Materials and methods}

Animals. Adult Sprague-Dawley rats, weighing 200 \pm 20 g were obtained from the Experimental Animal Center, Shanghai Medical College of Fudan University. Rats were bred and kept in special-pathogen-free (SPF) condition, with free access of food and water. All animal experiments were approved by the Ethics Committee of Shanghai Medical College of Fudan University and performed in accordance with institutional guidelines for animal experiments.

Isolation, cultivation and characterization of EPCs. The male rats were sacrificed by cervical dislocation and immersed in $75 \%$ alcohol for $8 \mathrm{~min}$ for sterilization. Subsequently, the skin and fascia were cut with eye scissors and the muscles were stripped. Then the femurs and tibias were isolated and placed in pre-cooled Dulbecco's modified Eagle's medium (DMEM; Gibco, Carlsbad, CA, USA). Afterwards, the bone marrow was flushed from femurs and tibias of the rats using a syringe with DMEM, collected in a 15-ml centrifuge tube and dissociated into a single-cell suspension by pipetting. Then the singlecell suspension was slowly transferred to a new centrifuge tube containing $10 \mathrm{ml}$ lymphocyte separation medium and centrifuged for $20 \mathrm{~min}$ at 2,000 rpm. The liquid in the middle layer was separated and resuspended with DMEM. After centrifugation at 1,000 rpm for $10 \mathrm{~min}$, EPCs were obtained and suspended with Endothelial Basal Medium-2 (EBM-2; Lonza, Basel, Switzerland), and inoculated in a 6-cm culture dish pre-coated with $0.1 \%$ fibronectin at $5 \times 10^{5}$ cells $/ \mathrm{ml}$. Cells were incubated in a $37^{\circ} \mathrm{C}$ and $5 \% \mathrm{CO}_{2}$ incubator. When cells were grown to $70-80 \%$ confluence, they were used for further analysis.
The cultured EPCs (passage 0) were digested with $0.25 \%$ trypsin-EDTA solution for $2 \mathrm{~min}$ at room temperature after washing with phosphate-buffered saline (PBS). Then the cells were collected, counted and resuspended with PBS containing $0.5 \%$ bovine serum albumin (BSA) at $1 \times 10^{8}$ cells $/ \mathrm{ml}$. Afterwards, the cells were incubated with FITC-conjugated antibodies against CD34, PE-conjugated antibodies against CD133 and VEGFR-2 at $4^{\circ} \mathrm{C}$ for $10 \mathrm{~min}$. After centrifugation, the harvested cells were smeared onto glass slides and observed under confocal microscopy.

In vitro assessments. The identified EPCs (passage 0) were seeded into 24 -well plates at $1 \times 10^{5}$ cells $/ \mathrm{ml}$ and treated with DMEM (control) and T $\beta 4$ at different concentrations $(0.05,0.1$ and $0.2 \mu \mathrm{M})$, respectively.

Cell viability. Twenty-four hours after $\mathrm{T} \beta 4$ treatment, $0.5 \%$ (w/v) 3-(4,5-dimethylthiazol-2-yl)-2,5-diphenyltetrazolium bromide (MTT) in PBS was added to each well and the mixture was incubated at $37^{\circ} \mathrm{C}$ for $4 \mathrm{~h}$. Afterwards, dimethylsulfoxide (DMSO) was added to the mixture and the mixture was incubated with gentle shaking for $10 \mathrm{~min}$. Cell viability was determined by the absorbance at $570 \mathrm{~nm}$ using a microplate reader. Three replicate trials were conducted for each concentration of $\mathrm{T} \beta 4$.

Hypoxia and serum deprivation treatment. Twenty-four hours before the experiment, DMEM was placed in a hypoxic chamber $\left(1 \% \mathrm{O}_{2}, 94 \% \mathrm{~N}_{2}\right.$ and $\left.5 \% \mathrm{CO}_{2}\right)$ for pretreatment. After cells were treated with $\mathrm{T} \beta 4$ at different concentrations, they were incubated in pretreated DMEM without fetal bovine serum (FBS) in the hypoxic chamber $\left(1 \% \mathrm{O}_{2}, 94 \% \mathrm{~N}_{2}\right.$ and $5 \% \mathrm{CO}_{2}$ ) for $12 \mathrm{~h}$. Subsequently, a portion of the cells was added together with $0.5 \% \mathrm{w} / \mathrm{v}$ MTT solution for detection of cell viability. The other portion of cells was stained with ethidium bromide and acridine orange (EB/AO) and observed under a fluorescence microscope. Five random fields in each well were analyzed for calculating surviving and apoptotic cells.

Cell migration. The changes in EPC migration after T $\beta 4$ treatment were measured in Transwell cell culture chambers with 6.5-mm diameter polycarbonate membrane filters ( $8-\mu \mathrm{m}$ pore). The Transwell chambers were placed in 24-well plates, and the membrane filters were coated with $40 \mathrm{ml}$ of Matrigel solution [diluted with FBS-free DMEM solution]. After drying, EPCs were seeded into the chamber at a density of $5 \times 10^{5} /$ chamber and then treated with $\mathrm{T} \beta 4$ at different concentrations. FBS-free EBM-2 was added into the upper chamber of the devise, whereas the lower chamber was filled with EBM-2 containing $5 \%$ FBS. After $12 \mathrm{~h}$ of incubation at $37^{\circ} \mathrm{C}$, non-migrated cells were removed from the upper surface of the membrane using a cotton swab. Then the filters were fixed in $90 \%$ alcohol for $30 \mathrm{~min}$ and stained with crystal violet for $10 \mathrm{~min}$. The migrated cells were observed under a microscope and determined by the absorbance at $600 \mathrm{~nm}$ using a microplate reader after addition of $10 \%$ acetic acid.

Angiogenesis assay. Firstly, the 96-well plates were filled with pre-cooled Matrigel solution (50 $\mu \mathrm{l}$ in each well) and placed in 
a cell culture chamber with $5 \% \mathrm{CO}_{2}$ at $37^{\circ} \mathrm{C}$ for $30 \mathrm{~min}$. Then EPCs were inoculated into the 96 -well plates at a density of $1 \times 10^{5} /$ well and treated with $\mathrm{T} \beta 4$ at different concentrations. In addition, 5\% FBS was added to each well and EPCs were incubated in $5 \% \mathrm{CO}_{2}$ at $37^{\circ} \mathrm{C}$ for $6 \mathrm{~h}$. Three different images from each well were captured, and the total tubule number was calculated by two independent investigators.

Western blot analysis. EPCs after treatment of $\mathrm{T} \beta 4$ at different concentrations were lysed with RIPA lysis buffer containing $10 \mathrm{mM}$ phenylmethylsulfonyl fluoride (PMSF). Then the lysates were isolated by centrifugation and total protein was quantified using a standard bicinchoninic acid (BCA) assay (Pierce, Rockford, IL, USA). After quantification, the proteins were separated using $10 \%$ sodium dodecyl sulfate-polyacrylamide gel electrophoresis (SDS-PAGE), and transferred onto a polyvinylidene difluoride membrane. The membranes were incubated in $5 \%$ milk in $0.1 \%$ Tris-buffered saline (TBS) at room temperature for $1 \mathrm{~h}$. Afterwards, the membranes were incubated with anti-Akt and anti-p-AKT antibodies (1:1,000; Santa Cruz Biotechnology, Inc., Santa Cruz, CA, USA). Subsequently, the membranes were incubated with horseradish peroxidase (HRP)conjugated secondary antibodies (Abcam, Cambridge, MA, USA) at a dilution of 1:5,000. Finally, the membranes were washed and visualized using an enhanced chemiluminescence system (GE Healthcare, Piscataway, NJ, USA).

MI model and treatment. MI was induced by surgical ligation of the left anterior descending coronary artery in 24 female rats. Firstly, the animals were anesthetized with ketamine $(80 \mathrm{mg} / \mathrm{kg})$ and placed in a supine position. Then they were intubated and mechanically ventilated with a rodent ventilator with a respiratory rate of 80 beats/min, and tidal volume of $7 \mathrm{ml}$. A left-side thoracotomy was performed to expose the heart. After removing the pericardium, the left arterial descending coronary artery was permanently ligated. After establishment of the MI model, rats were randomized into three groups, with 8 rats in each group: control group, EPC group and T $\beta 4$-EPC group. Rats in the control group received an intramyocardial injection of $100 \mu \mathrm{l}$ PBS; rats in the EPC group received an intramyocardial injection of $100 \mu \mathrm{l}$ PBS containing $2 \times 10^{6} \mathrm{EPCs}$; and rats in the T $\beta 4$-EPC group were administered $2 \times 10^{6}$ EPCs pretreated with $\mathrm{T} \beta 4(2 \mu \mathrm{M})$. Another 8 mice underwent a sham operation including every step except coronary ligation and were assigned into the sham group. Surgery was finally completed by chest closure and muscle and skin suture. Rats in each group were treated with penicillin after surgery to prevent infection.

Measurement of cardiac function. Four weeks after EPC injection, the cardiac function of all rats was monitored using an ultrasound system with a $15 \mathrm{MHz}$ probe, sample volume of $0.6 \mathrm{~mm}$ and scanning speed of $100 \mathrm{~mm} / \mathrm{sec}$. M-mode images were obtained by drawing an anatomical M-mode line perpendicular to the interventricular septum and left ventricular posterior wall. The measurements for left ventricular end-diastolic diameter (LVEDD), left ventricular end-systolic diameter (LVESD), left ventricular end-diastolic volume (LVEDV) and left ventricular end-systolic volume (LVESV) were carried out according to the recommendations of the American Society of Echocardiography. The ejection fraction of the left ventricle (EF) and fractional shortening (FS) were calculated using the Teichholz formula:

$$
\mathrm{EF}(\%)=[(\mathrm{LVEDV}-\mathrm{LVESV}) / \mathrm{LVEDV}] \times 100 \%
$$$$
\text { FS }(\%)=[(\text { LVEDD }- \text { LVESD }) / \text { LVEDD }] \times 100 \%
$$

The value of each parameter was obtained from three different cardiac cycles.

Histologic examination. After echocardiography, the rats were anesthetized with ketamine and the heart was removed from the open chest of the rats. Then the hearts were washed with normal saline, fixed in $4 \%$ paraformaldehyde for $24 \mathrm{~h}$, immersed in 15 and $30 \%$ sucrose in PBS for dehydration and embedded in OCT compound. Then the tissue samples were cut into 5- $\mu \mathrm{m}$ sections and stained with Masson's trichrome. Myocardial tissue and scar tissue in the infarcted area were observed under light microscopy and the epicardial perimeters of the infarcted area and the whole ventriculus sinister were assessed using Image-Pro Plus 6.0 software. The infarcted size was determined by the following formula:

Infarcted size $=$ epicardial perimeters of the infarcted area/epicardial perimeters of the whole ventriculus sinister $\mathrm{x} 100 \%$.

Immunohistochemistry. For immunohistochemistry, tissue sections were blocked in goat serum. Then the sections were incubated with mouse specific primary antibodies [anti-CD31 and smooth muscle actin- $\alpha(\alpha-$ SMA) $]$ at a dilution of $1: 100$ at $4^{\circ} \mathrm{C}$ overnight, followed by incubated with DyLight 594-conjugated and FITC-conjugated goat anti-mouse secondary antibodies at room temperature for $1 \mathrm{~h}$. Cell nuclei were stained with 4',6-diamidino-2-phenylindole (DAPI). Vascular structures positive for the expression of both CD31 and $\alpha$-SMA were observed under fluorescence microscopy at x 200 magnification. Five random fields from each slide were used to calculate the microvessel density and three slides selected from the upper, middle and lower region of the infarcted area of the heart were used for analysis.

Fluorescence in situ hybridization (FISH) for the $Y$-chromosome. Tissue sections were first immersed in PBS containing $0.2 \%$ Triton X-100. After washing with PBS, the sections were treated with $0.2 \mathrm{~N} \mathrm{HCl}$ solution for $20 \mathrm{~min}$ at room temperature and digested with $0.1 \mathrm{mg} / \mathrm{ml}$ proteinase $\mathrm{K}$ solution in a humidified atmosphere. Then probe buffer was added onto the slides at $37^{\circ} \mathrm{C}$ for $30 \mathrm{~min}$ to block non-specific binding. Afterwards, the sections were incubated with cDNA probe buffer containing $1 \mathrm{ng} / \mu \mathrm{l} \mathrm{Y}$-chromosome probe at $95^{\circ} \mathrm{C}$ for $10 \mathrm{~min}$ and at $37^{\circ} \mathrm{C}$ overnight. On the next day, the slides were washed with pre-warmed $2 \mathrm{X}$ SSC solution $[17.53 \mathrm{~g}$ of sodium chloride $(0.29 \mathrm{M}), 8.82 \mathrm{~g}$ of sodium citrate and distilled water in a final volume of $1,000 \mathrm{ml}, \mathrm{pH} 7.0], 2 \mathrm{X} \mathrm{SSC}$ solution and 0.1X SSC solution, respectively. After blocking with $5 \%$ goat serum for $5 \mathrm{~min}$, the slides were treated with FITC-labeled streptavidin and then incubated for $1 \mathrm{~h}$ at room temperature. Finally, the sections were immunostained with the anti-CD31 antibody at a dilution of 1:100. DAPI was used to stain cell nuclei. The distribution and endothelial differentiation of cells positive for Y-chromosome were observed under a microscope. 

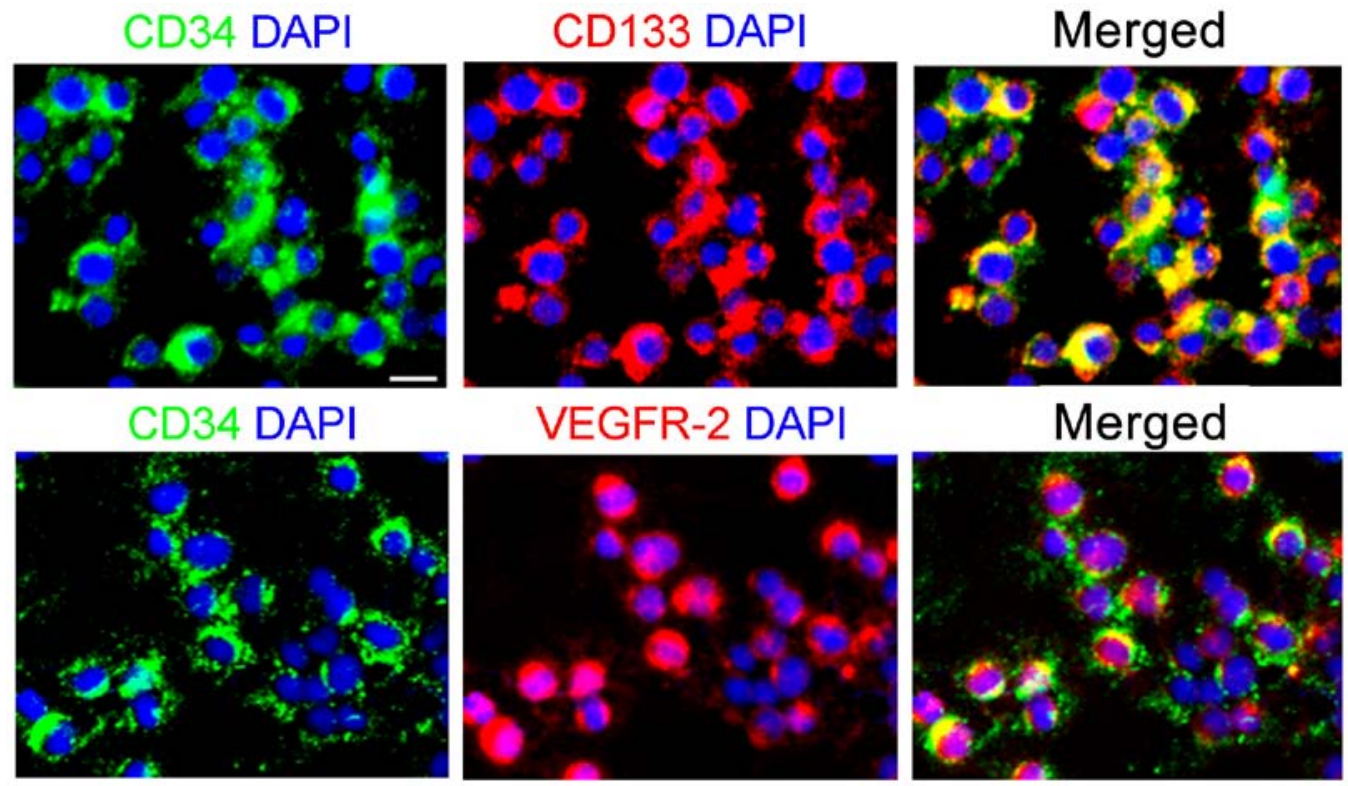

Figure 1. Identification of endothelial progenitor cells by detecting the expression of CD34, CD133 and VEGFR-2.

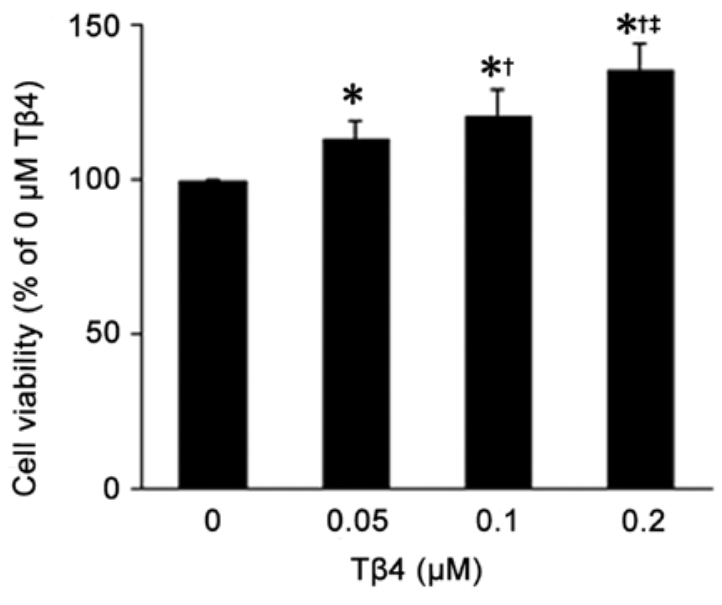

Figure 2. Cell viability of endothelial progenitor cells (EPCs) treated with thymosin $\beta 4$ (T $\beta 4$ ) at different concentrations [0 (DMEM), 0.05, 0.1 and $0.2 \mu \mathrm{M}]$. EPC viability was positively correlated to the increase in the T $\beta 4$ dose. ${ }^{*} \mathrm{P}<0.01$ compared to the $0 \mu \mathrm{M} \mathrm{T} \beta 4$ group; ${ }^{\dagger} \mathrm{P}<0.01$ compared to the $0.05 \mu \mathrm{M} \mathrm{T} \beta 4$ group; ${ }^{\ddagger} \mathrm{P}<0.01$ compared to the $0.1 \mu \mathrm{M} \mathrm{T} \beta 4$ group.

Statistical analysis. All statistical analysis was conducted with SPSS 19.0 software (SPSS Inc., Chicago, IL, USA). Data were expressed as mean \pm standard deviation (SD) and independent t-test was utilized to perform comparison between two groups. A value of $\mathrm{P}<0.05$ was considered to indicate a statistically significantly difference.

\section{Results}

Identification of EPCs. EPCs were isolated from bone marrow and cultured in a $37^{\circ} \mathrm{C}$ and $5 \% \mathrm{CO}_{2}$ incubator. Three days after inoculation, colony growth occurred on adherent cells. After additional culture of 2 days, the cells were grown to $80 \%$ confluence. The cells were spindle-shaped and covered with projections. The results from the immunofluorescent staining revealed that $>90 \%$ of the cells expressed CD34,
CD133 and VEGFR-2 (Fig. 1). The results indicate that the EPCs were successfully prepared.

$T \beta 4$ promotes the cell function of EPCs

T $\beta 4$ enhances EPC viability. As shown in Fig. 2, there was a significant increase in cell viability in the EPCs following treatment with $\mathrm{T} \beta 4$ compared to the viability of EPCs without $\mathrm{T} \beta 4$ treatment $(\mathrm{P}<0.05)$. The effects of $\mathrm{T} \beta 4$ in promoting EPC viability were in a dose-dependent manner $(0.05$ vs. $0.1 \mu \mathrm{M}$, 0.05 vs. $0.2 \mu \mathrm{M}$ and 0.1 vs. $0.2 \mu \mathrm{M}$ : $113.2 \pm 6.23$ vs. $120.9 \pm 8.73 \%$, $113.2 \pm 6.23$ vs. $135.7 \pm 8.71 \%$ and $120.9 \pm 8.73$ vs. $135.7 \pm 8.71 \%$, $\mathrm{P}<0.05)$.

T $\beta 4$ protects EPCs against hypoxia and serum deprivation. Based on the results from the MTT assay (Fig. 3A), compared to the EPCs without T $\beta 4$ treatment, there was an obvious increase in cell viability in the EPCs after T $\beta 4$ treatment at different concentrations $(\mathrm{P}<0.05)$ under hypoxia and serum deprivation and the growth-promoting effects were also in a dose-dependent manner. In addition, after staining with $\mathrm{EB} / \mathrm{AO}$, the apoptotic cells in the $\mathrm{T} \beta 4$ treatment groups were less than those without $\mathrm{T} \beta 4$ treatment (Fig. 3B).

$T \beta 4$ promotes EPC migration. As shown in Fig. 4A-D, the number of migrated cells in the $T \beta 4$ treatment group was increased compared to that in the control group. After staining with crystal violet, the numbers of migrated cells from each group were quantified. A significant increase in the number of migrated cells was observed in the $T \beta 4$ treatment group $(\mathrm{P}<0.05)$ and the migration-promoting effects of $\mathrm{T} \beta 4$ was in a dose-dependent manner (Fig. 4E).

$T \beta 4$ promotes EPC-based neovascularization. In each group, $6 \mathrm{~h}$ after inoculation of EPCs into Matrigel, most of the cells were covered with projections. These projections connected with each other, leading to the formation of tubular structure. Moreover, T $\beta 4$ promoted the formation of EPC-based vascular structure. As the concentration of T $\beta 4$ was increased, more tubular structures were observed (Fig. 5A-D). After quantification analysis, compared to the number of tubular structures 
A

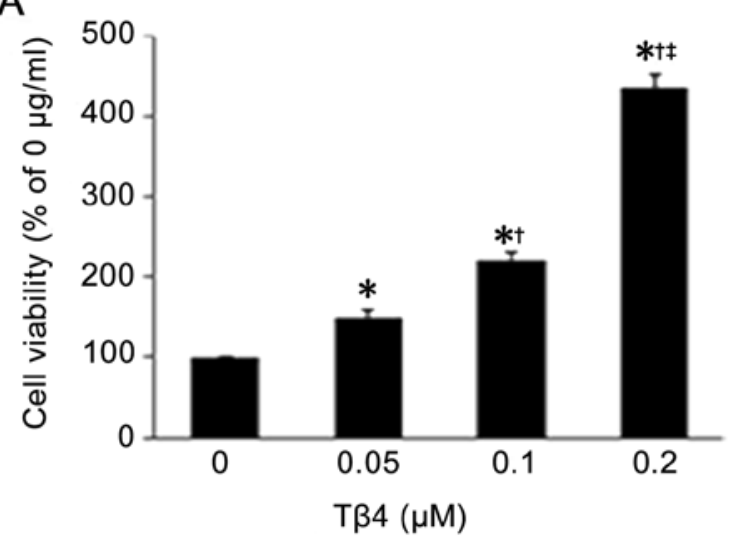

B
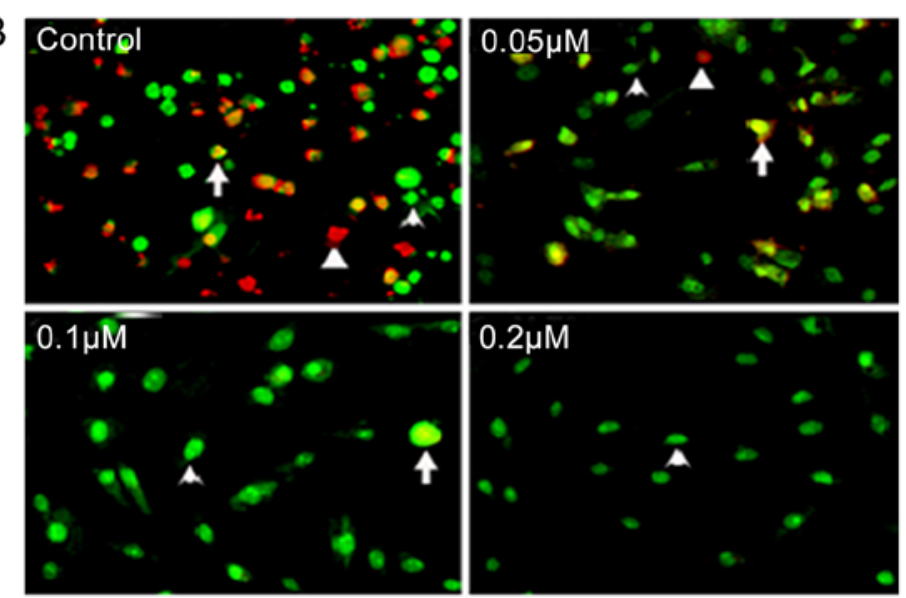

Figure 3. Thymosin $\beta 4$ (T $\beta 4$ ) protected endothelial progenitor cells (EPCs) from hypoxia and serum deprivation. EPCs were pretreated with T $\beta 4$ at different concentrations [0 (DMEM), $0.05,0.1$ and $0.2 \mu \mathrm{M}$ ]. (A) MTT analysis of EPC viability under hypoxia and serum deprivation. "P $<0.01$ compared to the $0 \mu \mathrm{M}$ $\mathrm{T} \beta 4$ group; ${ }^{\dagger} \mathrm{P}<0.01$ compared to the $0.05 \mu \mathrm{M} \mathrm{T} \beta 4$ group; ${ }^{\circ} \mathrm{P}<0.01$ compared to the $0.1 \mu \mathrm{M} \mathrm{T} \beta 4$ group. (B) EB/AO staining of EPC apoptosis. A number of apoptotic cells (long arrows) and necrotic cells (triangle) were viewed in the $0 \mu \mathrm{M} \mathrm{T} \beta 4$ group. There were less apoptotic cells and necrotic cells in the 0.05 and $0.1 \mu \mathrm{M} \mathrm{T} \beta 4$ group. In the $0.2 \mu \mathrm{M} \mathrm{T} \beta 4$ group, most of the EPCs were live cells (short arrows).
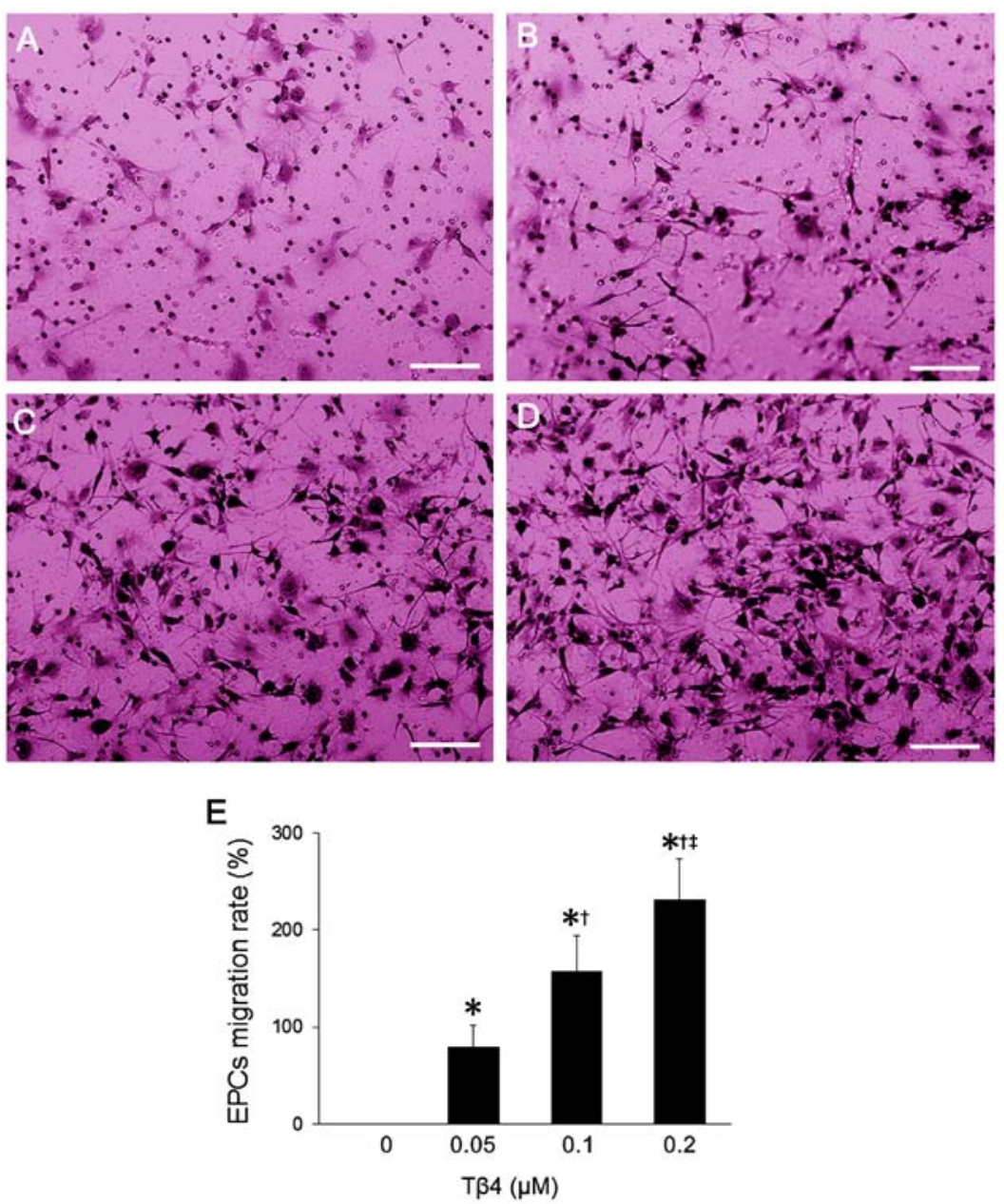

Figure 4. Thymosin $\beta 4$ (T $\beta 4$ ) promotes endothelial progenitor cell (EPC) migration. (A-D) The migrated cells in filters were observed under a microscope. Scale bar, $200 \mu \mathrm{m}$. (A) $0 \mu \mathrm{M}$ T $\beta 4$ group; (B) $0.05 \mu \mathrm{M}$ T $\beta 4$ group; (C) $0.1 \mu \mathrm{M} \mathrm{T} \beta 4$ group; (D) $0.2 \mu \mathrm{M}$ T $\beta 4$ group; (E) Quantified analysis of migrated EPCs. ${ }^{*} \mathrm{P}<0.01$ compared to the $0 \mu \mathrm{M}$ T $\beta 4$ group; ${ }^{~} \mathrm{P}<0.01$ compared to the $0.05 \mu \mathrm{M} \mathrm{T} \beta 4$ group; ${ }^{\circ} \mathrm{P}<0.01$ compared to the $0.1 \mu \mathrm{M} \mathrm{T} \beta 4$ group.

in the control group, there was a significant increase in EPCs treated with $\mathrm{T} \beta 4$ at different concentrations $(\mathrm{P}<0.05)$ (Fig. 5E).
In addition, the promoting-effect of $\mathrm{T} \beta 4$ on EPC-based neovascularization was in a dose-dependent manner. 

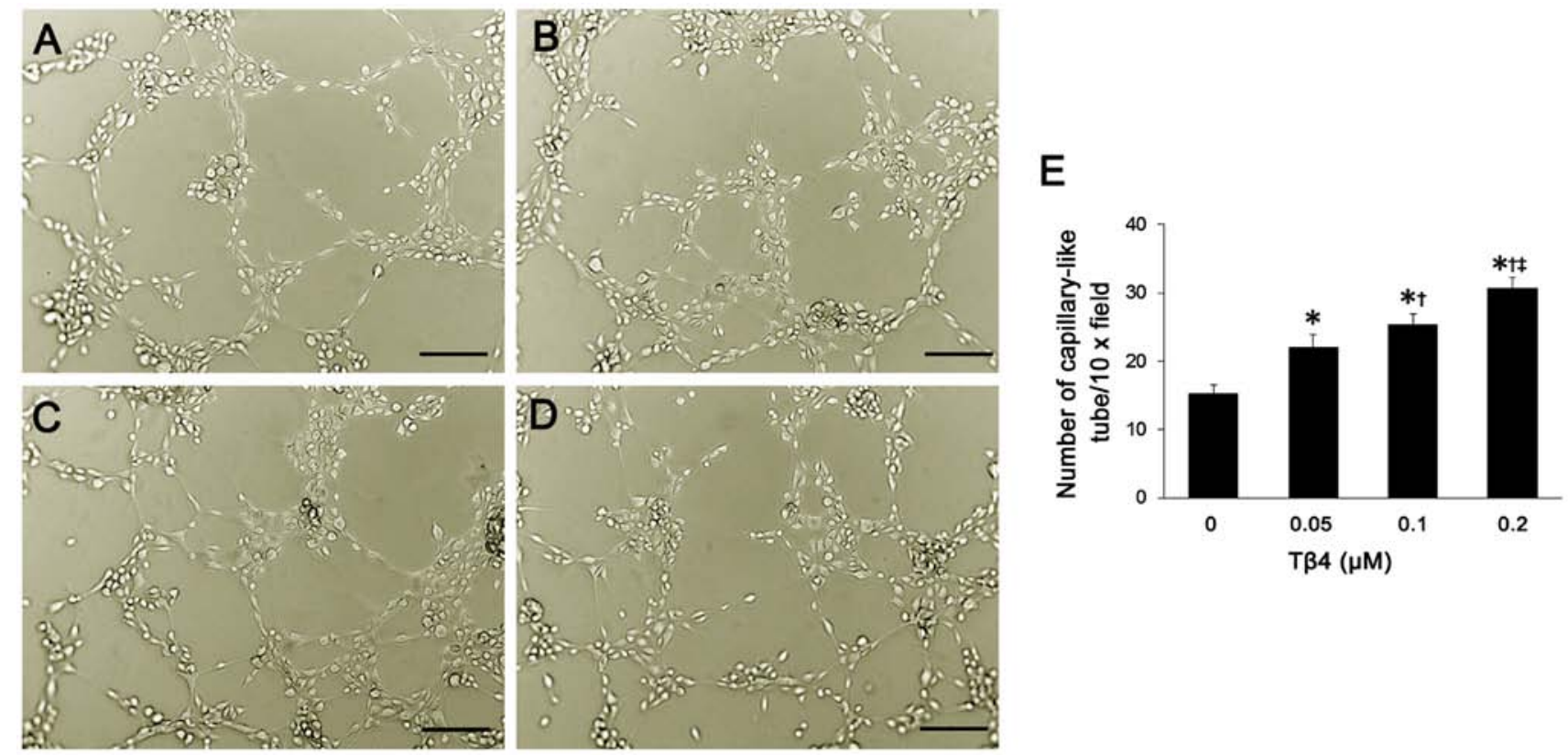

Figure 5. Thymosin $\beta 4$ (T $\beta 4$ ) promotes endothelial progenitor cell (EPC)-based tubule formation. (A-D) The tubular structure in Matrigel observed under a microscope. Scale bar, $200 \mu \mathrm{m}$; (A) $0 \mu \mathrm{M} \mathrm{T} \beta 4$ group; (B) $0.05 \mu \mathrm{M} \mathrm{T} \beta 4$ group; (C) $0.1 \mu \mathrm{M} \mathrm{T} \beta 4$ group; (D) $0.2 \mu \mathrm{M}$ T $\beta 4$ group; (E) quantified analysis of tubular structures. ${ }^{*} \mathrm{P}<0.01$ compared to the $0 \mu \mathrm{M}$ T $\beta 4$ group; ${ }^{\mathrm{P}}<0.01$ compared to the $0.05 \mu \mathrm{M} \mathrm{T} \beta 4$ group; ${ }^{\dagger} \mathrm{P}<0.01$ compared to the $0.1 \mu \mathrm{M} \mathrm{T} \beta 4$ group.
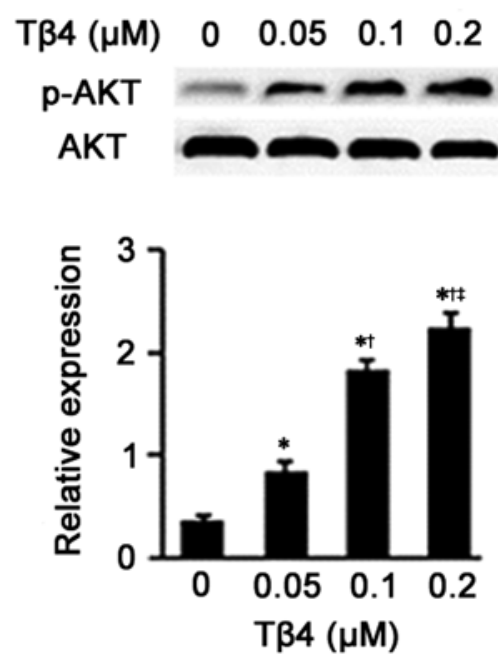

Figure 6. Thymosin $\beta 4$ (T $\beta 4$ ) increases the expression of p-Akt in endothelial progenitor cells (EPCs). EPCs were pretreated with T $\beta 4$ at different concentrations [0 (DMEM), 0.05, 0.1 and $0.2 \mu \mathrm{M}$ ]. ${ }^{*} \mathrm{P}<0.01$ compared to the $0 \mu \mathrm{M}$ $\mathrm{T} \beta 4$ group; ${ }^{\dagger} \mathrm{P}<0.01$ compared to the $0.05 \mu \mathrm{M} \mathrm{T} \beta 4$ group; ${ }^{\dagger} \mathrm{P}<0.01$ compared to the $0.1 \mu \mathrm{M} \mathrm{T} \beta 4$ group.

$T \beta 4$ upregulates the expression of $p$-Akt. Following the results from the western blot analysis (Fig. 6), an obviously upregulation of the expression of phosphorylated Akt was noted in the EPCs treated with T $\beta 4$ at different concentrations compared to the EPCs treated with DMEM $(\mathrm{P}<0.05)$. Additionally, as the dose of $\mathrm{T} \beta 4$ increased, the promoting effects of $\mathrm{T} \beta 4$ on $\mathrm{p}$-Akt expression were also elevated ( 0.05 vs. $0.1 \mu \mathrm{M}, 0.05$ vs. $0.2 \mu \mathrm{M}$ and 0.1 vs. $0.2 \mu \mathrm{M}, \mathrm{P}<0.05$ ).

Transplantation of T $\beta 4$-treated EPCs improves cardiac function in rats with MI. Based on the results of echocardiography, transplantation of the EPCs or T $\beta 4$-EPCs both reduced left ventricular chamber and increased the left ventricular wall thickness in rats with MI (Fig. 7A). After statistical analysis (Fig. 7B-G), compared to the rats in the control group, both $\mathrm{EF}$ and FS were significantly increased in the rats transplanted with EPCs and T $\beta 4$-EPCs $(\mathrm{P}<0.05)$. Moreover, both parameters were also significantly higher in the rats transplanted with T $\beta 4$-EPCs than those with EPCs $(\mathrm{P}<0.05)$. Furthermore, both LVESD and LVESV were significantly decreased in the rats transplanted with T $\beta 4$-EPCs compared to the rats in the control group $(\mathrm{P}<0.05)$.

TR4 promotes EPC-based cardiac repair in rats with MI. Masson's trichrome staining showed an obvious expansion of the left ventricular chamber and thinning of the left ventricular wall in rats that underwent surgical ligation of the left anterior descending coronary artery. Moreover, most of the myocardium in the infarcted area was replaced by scar tissue. Whereas, in the MI-induced rats transplanted with EPCs or T $\beta 4$-EPCs, the left ventricular chamber was smaller, the left ventricular wall was thicker and there was much less scar tissue and more myocardial cells compared to the rats in the control group (Fig. 8A). Statistical results indicated that in rats transplanted with T $\beta 4$-EPCs the left ventricular wall thickness was significantly larger and the infarcted size was significantly smaller than these parameters in the control and EPC groups $(\mathrm{P}<0.05)$ (Fig. 8B and $\mathrm{C})$.

T $\beta 4$ promotes EPC-based angiogensis in rats with MI. Angiogenesis was observed in the marginal zone of the infarcted area as confirmed by immunofluorescence. Transplantation with EPCs promoted angiogenesis as confirmed by the increase in CD31- and $\alpha$ SMA-positive cells in the infarcted area (Fig. 9A). In addition, transplantation with T $\beta 4$-EPCs showed more promoting effects on angiogenesis. Based on the statistical results, the microvessel density was 
A

Sham

Control

EPCs

Tß4-EPCs
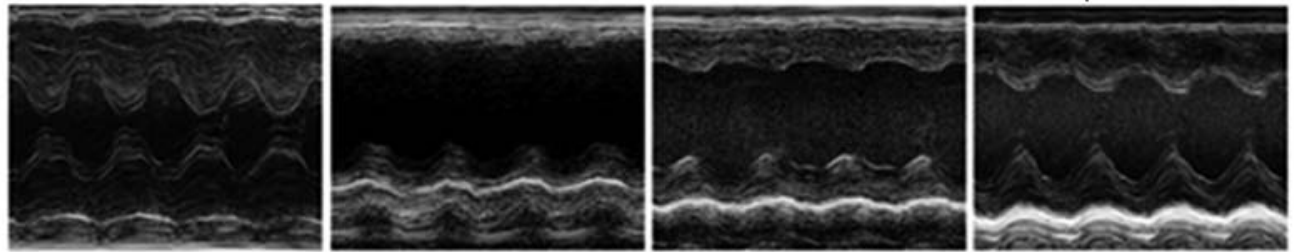

B

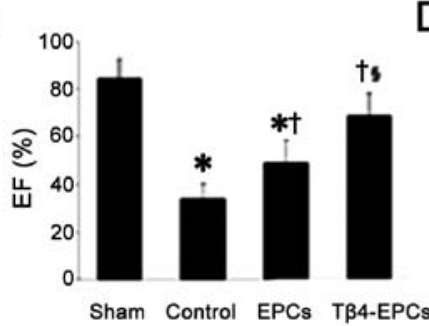

D

F

C
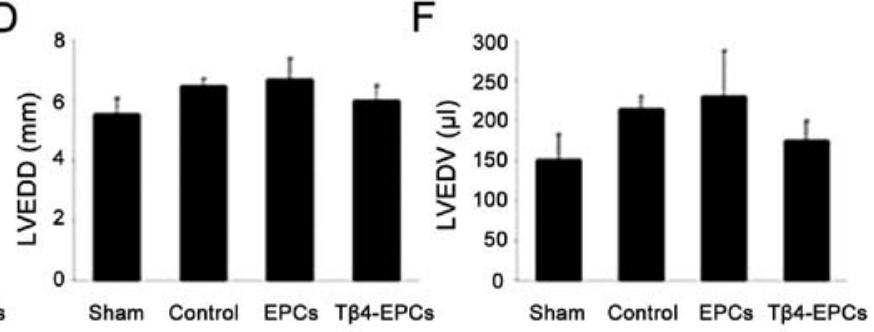

E
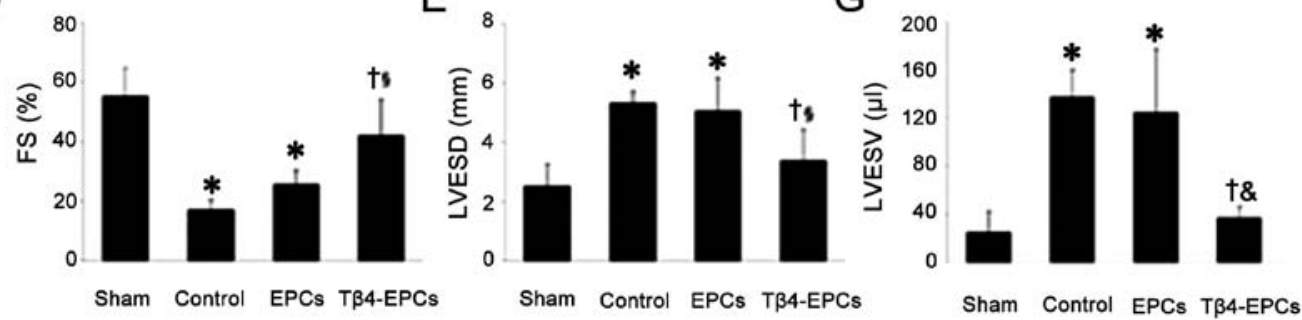

Figure 7. Thymosin $\beta 4$ (T $\beta 4$ )-treated endothelial progenitor cell (EPC) transplantation improves cardiac function in rats with myocardial infarction (MI). (A) Two-dimensional echocardiograms. Compared to the rats in the control group, the diameter of the ventriculus sinister was reduced in both the EPC and T 34 -EPC groups. In addition, the left ventricular wall thickness was also increased in the EPC and T $\beta 4$-EPC group compared to the control group. (B-G) Changes in the ejection fraction of the left ventricle (EF), fractional shortening (FS), left ventricular end-diastolic diameter (LVEDD), left ventricular end-systolic diameter (LVESD), left ventricular end-diastolic volume (LVEDV) and left ventricular end-systolic volume (LVESV) in rats with different treatments. "P $<0.01$ compared to the $0 \mu \mathrm{M} \mathrm{T} \beta 4$ group; ${ }^{ } \mathrm{P}<0.01$ compared to the $0.05 \mu \mathrm{M} \mathrm{T} \beta 4$ group; ${ }^{\circ} \mathrm{P}<0.01$ compared to the $0.1 \mu \mathrm{M} \mathrm{T} \beta 4$ group.

A

A Sham

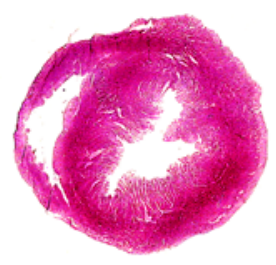

B

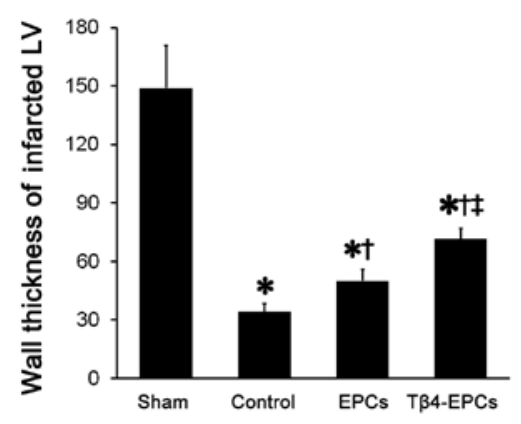

EPCs

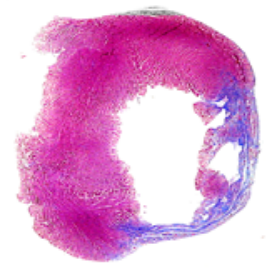

C

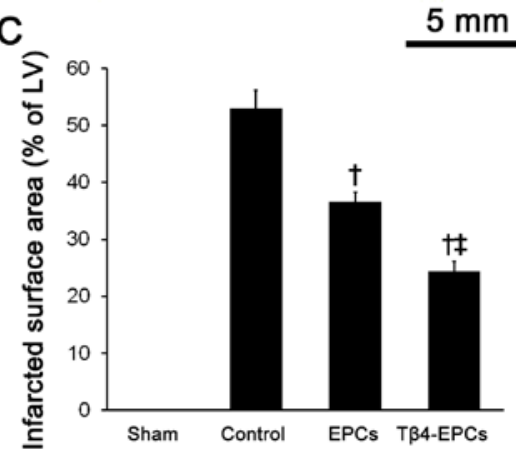

Figure 8. Thymosin $\beta 4$ (T $\beta 4$ )-treated endothelial progenitor cell (EPC) transplantation promotes cardiac repair of rats with myocardial infarction (MI). (A) Morphological changes in the left ventrical (LV) in rats after different treatments as detected by Masson's trichrome staining. Four weeks after surgical ligation, there was an obvious expansion of the LV chamber and the LV wall was thinner compared to the sham group. In the infarcted area, the myocardial cells (red) were decreased, instead of fibrous tissue (blue). Compared to the rats in the control group, rats transplanted with EPCs and T $\beta 4$-EPCs had an obviously smaller chamber and a thicker ventricular wall. (B) Quantified analysis of wall thickness of infarcted LV. (C) Quantified analysis of infarcted area. ${ }^{*} \mathrm{P}<0.01$ compared to the $0 \mu \mathrm{M} \mathrm{T} \beta 4$ group; ${ }^{\mathrm{P}} \mathrm{P}<0.01$ compared to the $0.05 \mu \mathrm{M} \mathrm{T} \beta 4$ group; ${ }^{ } \mathrm{P}<0.01$ compared to the $0.1 \mu \mathrm{M} \mathrm{T} \beta 4$ group.

significantly higher in rats transplanted with T $\beta 4$-EPCs than that in rats in the EPC and control groups $(\mathrm{P}<0.05)($ Fig. 9B).
Furthermore, based on the results from FISH, Y-chromosome-positive cells were observed in the marginal 


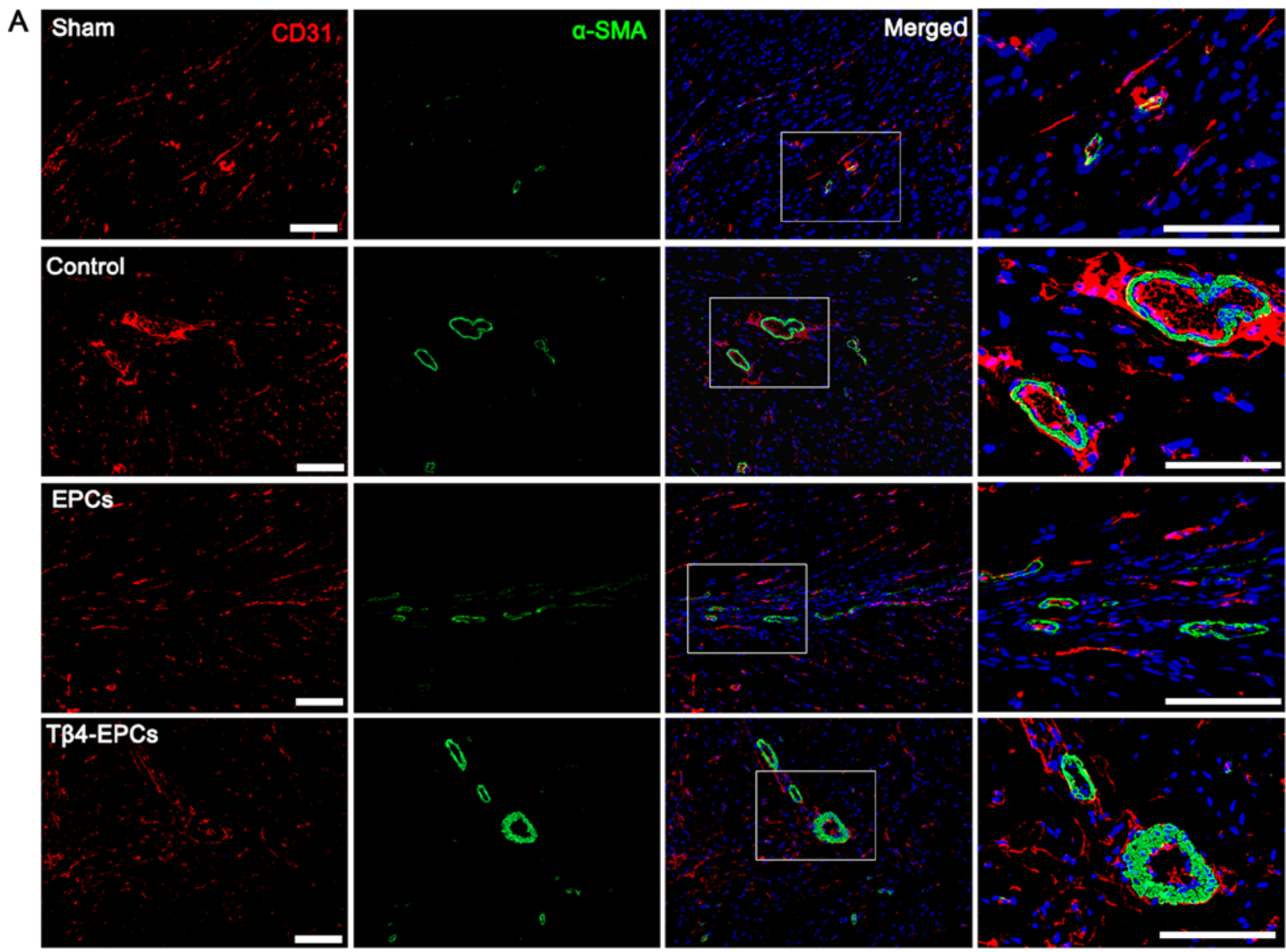

B

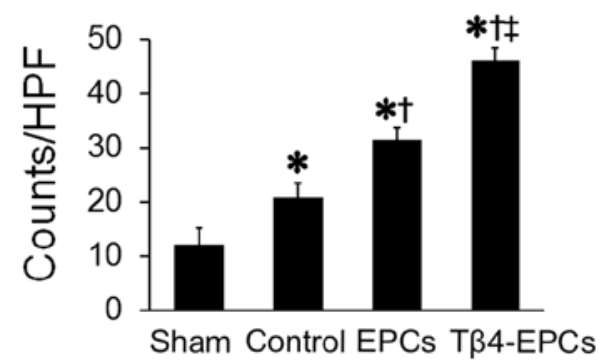

C

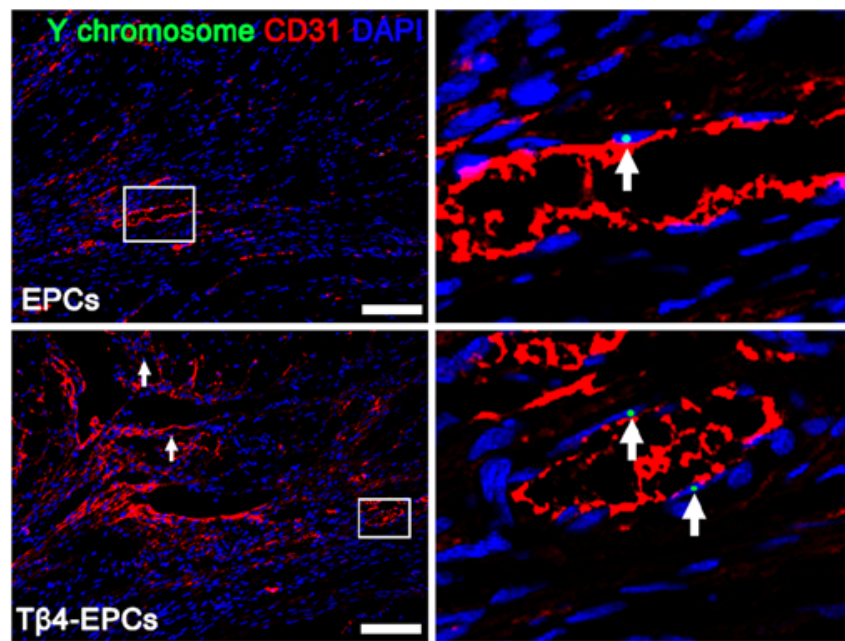

Figure 9. Thymosin $\beta 4$ (T $\beta 4$ )-treated endothelial progenitor cell (EPC) transplantation promotes EPC-based neovascularization in rats with myocardial infarction (MI). (A) Neovascularization as detected by immunostaining for CD31 and $\alpha$-SMA. Four weeks after infarction compared to the rats in the control group, there was an obvious increase in microvessel density in the infarcted area of rats from the EPC and T $\beta 4$-EPC group. Scale bar, $100 \mu \mathrm{m}$. (B) Quantified analysis of microvessel density in the infarcted area of rats after different treatments. ${ }^{*} \mathrm{P}<0.01$ compared to the $0 \mu \mathrm{M}$ T $\beta 4$ group; ${ }^{\circ} \mathrm{P}<0.01$ compared to the $0.05 \mu \mathrm{M} \mathrm{T} \beta 4$ group; ${ }^{\ddagger} \mathrm{P}<0.01$ compared to the $0.1 \mu \mathrm{M} \mathrm{T} \beta 4$ group. (C) EPC-based neovascularization as detected by fluorescence in situ hybridization (FISH) for the Y-chromosome. More surviving cells involved in tubule formation were observed in the T $\beta 4$-EPC-transplanted rats than in rats in the EPC and control group. Scale bar, $100 \mu \mathrm{m}$.

zone of the infarcted area, which constitutes the endothelial tissue. There were a higher number of Y-chromosome-positive cells in rats transplanted with T $\beta 4$-EPCs than the number in rats transplanted with EPCs $(\mathrm{P}<0.05)$ (Fig. 9C).

\section{Discussion}

The aim of the present study was to explore the cardioprotective effects of the transplantation of T $\beta 4$-treated EPCs in rats 
with MI. Both in vivo and in vitro experiments were conducted. $\mathrm{T} \beta 4$ is a pleiotropic factor involved in a wide variety of physiological and pathological processes. As described previously, $\mathrm{T} \beta 4$ promotes cell migration through binding actin and regulating the balance between polymerization and depolymerization of actin (20). In addition, T $\beta 4$ also modulates the synthesis and secretion of various cytokines including laminin-5, intercellular adhesion molecule (ICAM)-1 and matrix metalloproteinase-2 (MMP-2) to promote cell adhesion and migration (21). Recently, $\mathrm{T} \beta 4$ has been reported to exert a profound cardioprotective effect (22). T $\beta 4$ has been shown to be involved in the protection and regeneration of injured or damaged tissues. It also promotes angiogenesis by stimulating endothelial cell adhesion and migration, tubule formation, as well as EPC differentiation into endothelial cells (23). For the in vitro experiments in our study, $\mathrm{T} \beta 4$ promoted $\mathrm{EPC}$ survival, migration and EPC-based tubule formation, all of which were consistent with previous studies. In addition, EPC survival in the hypoxia and ischemic microenvironment of injured or damaged tissues is the key to EPC transplantation for treating cardiac diseases. In our study, T $\beta 4$ also protected EPCs from hypoxia and serum deprivation, which may be attributed to the protective effects of $\mathrm{T} \beta 4$ on mitochondria by reducing cytochrome enzyme $c$ release and upregulating the expression of Bcl-2 (24).

The Akt signaling pathway plays an important role in T $\beta 4$-mediated biological processes. After binding to adaptor protein LIMS1 and integrin-linked kinase (ILK), T $\beta 4$ activates the Akt signaling pathways, thus promoting cell migration (22). Additionally, $\mathrm{T} \beta 4$ decreases the expression of caspase-3 and caspase- 9 by activating the ILK-Akt signaling pathway under serum deprivation, then suppresses cell apoptosis (24). Consistent with a study by Qiu et al (25), T $\beta 4$ increased the expression of $\mathrm{p}$-Akt, indicating that the Akt signaling pathway was activated by $\mathrm{T} \beta 4$, which may be the mechanism underlying the promoting effects of $\mathrm{T} \beta 4$ on EPC viability, migration and angiogenesis. In addition, this mechanism was also confirmed in nude mice, and the same conclusion was obtained. All of this evidence indicates that the pathway of T $\beta 4$-induced EPC migration in vitro was consistent with that in vivo.

We also established an MI model by surgical ligation of the left anterior descending coronary artery in rats. A previous study indicated that EPC transplantation after MI can improve cardiac function and promote angiogenesis in the damaged myocardium (26). In the present study, compared to the control group, rats with EPC transplantation had improved cardiac function, smaller myocardial infarcted size and higher microvessel density. However, the low survival rate of EPCs limits the expanded application of EPC transplantation for treating MI (17). EPCs pretreated with T $\beta 4$ were also transplanted into rats with MI. Based on the results from our study, T $\beta 4$-treated EPCs significantly improved cardiac function in rats at 4 weeks post-infarction confirmed by the elevated levels of EF and FS and increase in the left ventricular wall thickness. Moreover, T $\beta 4$-treated EPCs obviously decreased the infarcted size and promoted cardiac repair in the MI model. Our findings were consistent with a previous study (27). Furthermore, T $\beta 4$ also promoted EPC-based neovascularization as confirmed by the significant increase in CD31- and aSMA-positive cells and Y-chromosome-positive cells. Due to the massive false-positive results provided by the $\alpha$-SMA antibody, the flow cytometry was restricted and the doublepositive immunostaining method was selected in this study. In spite of this, the immunostaining also provided us with significant information for this comparison. All of these results indicated that $\mathrm{T} \beta 4$ promoted cardioprotective effects of EPC transplantation in $\mathrm{MI}$.

Collectively, T $\beta 4$ is able to promote EPC survival, migration, tubule formation and also protect EPCs from hypoxia and serum deprivation, which may be attributed to the activation of the Akt signaling pathway. Additionally, the transplantation and survival of EPCs in MI can be increased by pretreatment with T $\beta 4$. Treatment with both EPCs and T $\beta 4$ can obviously improve cardiac function, promote cardiac repair and stimulate neovascularization in rats with MI.

\section{Acknowledgements}

This study was supported by the National Natural Science Foundation of China (grant no. 81270200 and grant no. 81470385) and the Scientific Research Foundation of State Education Commission (grant no. 20130071110080).

\section{References}

1. Mozaffarian D, Benjamin EJ, Go AS, Arnett DK, Blaha MJ, Cushman M, Das SR, de Ferranti S, Després JP, Fullerton HJ, et al: Heart Disease and Stroke Statistics-2016 Update: A report from the American Heart Association. Circulation 133: e38-e360, 2016.

2. Diseases NCFC: Report on cardiovascular disease in China 2014. Encyclopedia of China Publishing House, 2015.

3. White HD and Chew DP: Acute myocardial infarction. Lancet 372: 570-584, 2008.

4. Hochman JS, Lamas GA, Buller CE, Dzavik V, Reynolds HR, Abramsky SJ, Forman S, Ruzyllo W, Maggioni AP, White H, et al; Occluded Artery Trial Investigators: Coronary intervention for persistent occlusion after myocardial infarction. $\mathbf{N}$ Engl J Med 355: 2395-2407, 2006.

5. Keeley EC, Boura JA and Grines CL: Primary angioplasty versus intravenous thrombolytic therapy for acute myocardial infarction: A quantitative review of 23 randomised trials. Lancet 361: 13-20, 2003.

6. White H; Hirulog and Early Reperfusion or Occlusion (HERO)-2 Trial Investigators: Thrombin-specific anticoagulation with bivalirudin versus heparin in patients receiving fibrinolytic therapy for acute myocardial infarction: The HERO-2 randomised trial. Lancet 358: 1855-1863, 2001.

7. Freemantle N, Cleland J, Young P, Mason J and Harrison J: beta Blockade after myocardial infarction: systematic review and meta regression analysis. BMJ 318: 1730-1737, 1999.

8. Verma $\mathrm{S}$ and Strauss M: Angiotensin receptor blockers and myocardial infarction. BMJ 329: 1248-1249, 2004.

9. McMurray J, Køber L, Robertson M, Dargie H, Colucci W, Lopez-Sendon J, Remme W, Sharpe DN and Ford I: Antiarrhythmic effect of carvedilol after acute myocardial infarction: Results of the Carvedilol Post-Infarct Survival Control in Left Ventricular Dysfunction (CAPRICORN) trial. J Am Coll Cardiol 45: 525-530, 2005.

10. Yang X, Cohen MV and Downey JM: Mechanism of cardioprotection by early ischemic preconditioning. Cardiovasc Drugs Ther 24: 225-234, 2010.

11. Bergmann O,Bhardwaj RD, Bernard S,Zdunek S, Barnabé-HeiderF, Walsh S, Zupicich J, Alkass K, Buchholz BA, Druid H, et al: Evidence for cardiomyocyte renewal in humans. Science 324: 98-102, 2009.

12. Werner N, Kosiol S, Schiegl T, Ahlers P, Walenta K, Link A, Böhm $\mathrm{M}$ and Nickenig G: Circulating endothelial progenitor cells and cardiovascular outcomes. N Engl J Med 353: 999-1007, 2005.

13. Yao EH, Fukuda N, Matsumoto T, Katakawa M, Yamamoto C, Han Y, Ueno T, Kobayashi N and Matsumoto K: Effects of the antioxidative $\beta$-blocker celiprolol on endothelial progenitor cells in hypertensive rats. Am J Hypertens 21: 1062-1068, 2008. 
14. Sen S, Merchan J, Dean J, Ii M, Gavin M, Silver M, Tkebuchava T, Yoon YS, Rasko JE and Aikawa R: Autologous transplantation of endothelial progenitor cells genetically modified by adenoassociated viral vector delivering insulin-like growth factor-1 gene after myocardial infarction. Hum Gene Ther 21: 1327-1334, 2010 .

15. Dubois C, Liu X, Claus P, Marsboom G, Pokreisz P, Vandenwijngaert S, Dépelteau H, Streb W, Chaothawee L, Maes F et al: Differential effects of progenitor cell populations on left ventricular remodeling and myocardial neovascularization after myocardial infarction. J Am Coll Cardiol 55: 2232-2243, 2010.

16. Higuchi T, Anton M, Dumler K, Seidl S, Pelisek J, Saraste A, Welling A, Hofmann F, Oostendorp RA, Gansbacher B, et al: Combined reporter gene PET and iron oxide MRI for monitoring survival and localization of transplanted cells in the rat heart. J Nucl Med 50: 1088-1094, 2009.

17. Yao Y, Li Y, Ma G, Liu N, Ju S, Jin J, Chen Z, Shen C and Teng G: In vivo magnetic resonance imaging of injected endothelial progenitor cells after myocardial infarction in rats. Mol Imaging Biol 13: 303-313, 2011.

18. Kupatt C, Horstkotte J, Vlastos GA, Pfosser A, Lebherz C, Semisch M, Thalgott M, Büttner K, Browarzyk C, Mages J, et al: Embryonic endothelial progenitor cells expressing a broad range of proangiogenic and remodeling factors enhance vascularization and tissue recovery in acute and chronic ischemia. FASEB J 19: 1576-1578, 2005.

19. Smart N, Risebro CA, Clark JE, Ehler E, Miquerol L, Rossdeutsch A, Marber MS and Riley PR: Thymosin $\beta 4$ facilitates epicardial neovascularization of the injured adult heart. Ann NY Acad Sci 1194: 97-104, 2010.

20. Sosne G, Xu L, Prach L, Mrock LK, Kleinman HK, Letterio JJ, Hazlett LD and Kurpakus-Wheater M: Thymosin beta 4 stimulates laminin-5 production independent of TGF-beta. Exp Cell Res 293: 175-183, 2004.
21. Yan L, Guan W, Hu Y, Xiaofan Y, Songshan X, Liya N and Yongzhe C: Recombinant thymosin $\beta 4$ accelerates skin wound healing by regulating ICAM-1, MMP-2 and LN-5. J Tissue Engineering and Reconstructive Surgery 163: 142-145, 2008.

22. Bock-Marquette I, Saxena A, White MD, Dimaio JM and Srivastava D: Thymosin $\beta 4$ activates integrin-linked kinase and promotes cardiac cell migration, survival and cardiac repair. Nature 432: 466-472, 2004

23. Smart N, Risebro CA, Melville AA, Moses K, Schwartz RJ, Chien KR and Riley PR: Thymosin $\beta 4$ induces adult epicardial progenitor mobilization and neovascularization. Nature 445: 177-182, 2007.

24. Sosne G, Siddiqi A and Kurpakus-Wheater M: Thymosin- $\beta 4$ inhibits corneal epithelial cell apoptosis after ethanol exposure in vitro. Invest Ophthalmol Vis Sci 45: 1095-1100, 2004.

25. Qiu FY, Song XX, Zheng H, Zhao YB and Fu GS: Thymosin $\beta 4$ induces endothelial progenitor cell migration via PI3K/Akt/eNOS signal transduction pathway. J Cardiovasc Pharmacol 53: 209-214, 2009.

26. Burlacu A, Grigorescu G, Rosca AM, Preda MB and Simionescu M: Factors secreted by mesenchymal stem cells and endothelial progenitor cells have complementary effects on angiogenesis in vitro. Stem Cells Dev 22: 643-653, 2013.

27. Chang ZT, Hong L, Wang H, Lai HL, Li LF and Yin QL: Application of peripheral-blood-derived endothelial progenitor cell for treating ischemia-reperfusion injury and infarction: A preclinical study in rat models. J Cardiothorac Surg 8: 33, 2013. 